\title{
Review on Term Structure
}

\author{
Jiemin Huang \\ Shenzhen Institute of Information Technology2188 Longxiang Boulevard, Longgang District \\ Shenzhen City, People's Republic of China, 086-518172 \\ huang_jiemin819@126.com
}

Keywords: Term structure; $\mathrm{N}$ factors; Affine model

\begin{abstract}
Domestic and foreign scholars on corporate bonds affine term structure models with varying degrees of research, the results is very rich. We can predict bond forward rates for Treasury bonds, the current yield term structure includes information of long-term maturity structure. For example, if a bond yield curve is steeper than usual, the long maturity bond yields will be reduced over time. This prediction depends only on the relationship between the yield time series behavior, it can extract more information from the current term structure, improve prediction. Research abroad Interest Rate Term Structure affine model are as follows.
\end{abstract}

\section{Introduction}

Many foreign scholars study found that three-factor model can fit the observed data. Dai, Singleton (2000) analyzed the affine term structure models differ in structure and terms of goodness of fit. These models simulate the correlation risk factors and volatility in terms of advantages and disadvantages [1]. He $\mathrm{N}$ factor affine model is extended to $\mathrm{N}+1$ factor affine model. Especially for three-factor model, based on theoretical analysis and research of other scholars, it showed three-factor model to better fit the historical interest rate curve. Vasicek (1977) and Cox, Ingersoll, Ross (1985) assumed that the instantaneous short rate $\mathrm{r}(\mathrm{t})$ is the state vector $\mathrm{N}$ factor $\mathrm{Y}(\mathrm{t})$ of affine equation [2-3], that is, $r(t)=\alpha_{0}+\alpha_{y}^{\prime} Y(t), Y(t)$ is Gaussian and the square root of diffusion. Some scholars univariate Markov model short-term rates to be extended, the introduction of $r(t)$ of the long-term average random $\theta(t)$ and the volatility $\mathrm{v}(\mathrm{t})$, short-term interest rates affine model: $d r(t)=(\theta-r(t)) d t+\sqrt{v} d B(t)$.

Duffee (2002) that the affine model cannot predict the expected rate of return bonds, he believes that the assumed yield better predict when subject to random walk, he thought that the reason for the failure of those models: risk compensation risk covariance, the change is not an independent risk compensation, interest rate volatility associated with it, he put forward the essence of affine model, the model maintains the advantages of the standard model, but the model is such that the risk of changes in interest rates and the volatility of interest rates independent of each other, studies have shown that this prediction has an important role in the future when yields [4]. Jong (2000) in conjunction with time-series cross-sectional information on affine term structure model is analyzed, he performed with the discrete Kalman filter analysis of continuous process time factor. It found that three-factor model can fit cross-section and dynamic term structure model [5]. Duffie, Kan (1996) using a continuous multi-factor model arbitrage-free term structure of interest rates, the yield was found to obey a fixed expiration time stochastic volatility multi-parameter Markov diffusion process. He assumes zero-coupon bond yields depend on the chosen rate of return based group [6]. The authors also used with jump diffusion interest rate term structure to solve the problem.

Longstaff, Schwartz (1995) to assess the value of having a corporate bond default and interest rate risk using a simple method. Fixed and floating rate valuation model for this approach comes from the closed-form model of bond pricing and hedging risk corporate bonds provides a new perspective. The authors found that the risk of default and the relationship between interest rates have a major impact on credit spreads. He used the corporate bond data were analyzed and found 
negative correlation between interest rates and credit spreads, also found that the risk of long-term bonds depends on interest rates. These empirical results are consistent with the results of the valuation model. Value of total assets of the company on behalf of the $\mathrm{V}, \mathrm{V}$ dynamic changes as follows: $d v=\mu V d t+\sigma v d z_{1}, \sigma$ is a constant, $z_{1}$ is the standard Wiener process. The authors used $\mathrm{r}$ represents the short-term risk-free rate. $\mathrm{R}$ dynamic changes as follows: $d r=(\varepsilon-\beta r) d t+\propto d z_{2} \circ \varepsilon, \beta, \propto$ is a constant, $z_{2}$ is the standard Wiener process, $d z_{1}$ and $d z_{2}$ instantaneous correlation is $\rho d t$. Based on this model the authors built the model [7].

Asileiou (2006) with a maturity of no probability of default bonds ahead of the defaulted bonds valuation, in this measurement, he found that the same semi-Markov nature. He found that the probability of a forward transfer relationship with the true probability equation sequence between the sequences. He also studied the term structure of credit spreads and risk premiums under the assumption that the estimated transition probabilities provide a forward algorithm [8]. Lamoureux, Witte (2002) Bayesian estimation method of Cox, Ingersoll, Ross (1985) term structure model in empirical analysis of time series and cross-section restrictions for analysis [9]. He found time series data limitations and the two-factor model of consistency. However, restrictions on the cross-section of the model and data inconsistencies. He found that three-factor model more significant, but time series fitting results deteriorated.

Many scholars added default factors in the bond term structure model. Duan, Simonato (1999) is the estimated state-space parameters to build the index term structure model. He Kalman filtering method, given only conditional mean and conditional variance. The model allows the observed yield to maturity there is an error, and can handle bond yields [10] have a different expiration time.

Duarte (2004) attempts to solve the conflict in the affine term structure model fits the average interest rate and interest rate volatility terms. His risk of price parameters, find parametric approach cannot effectively solve the contradiction between the two, he also found that the affine term structure models, some sustained state variables, the risk of price parameters of the lack of flexibility [11]. Dai, Singleton (2002) found that the slope of the yield curve is a linear function of income, which is in conflict with the traditional expectation theory [12]. Cheridito, Filipovic, Kimmel (2007) extends the measure affine revenue model market price of risk, and use it for US Treasury data analysis, empirical results significantly. Fitting of time series analysis to improve. He used no-arbitrage conditions, the square root of the affine model of multi-type variable income, the results are remarkable. Its findings can also be used for other asset pricing model [13]. Lando (1998) and the establishment of bonds may default credit derivatives model that takes into account market risk factors and credit risk models to solve the ordinary interest rate term structure model to estimate the technical problem of credit risk exposure. He showed how the bonds with different credit ratings affine term structure model and price model, he enclosed empirical analysis affine structure model of single factor [14].

Jarrow, Turnbull (1995) provides a new way for derivatives pricing and hedging credit risk. There are two forms of credit risk. The first is the existence of the underlying assets of derivatives risk of default, the second is derived from the bond seller's risk of default. He put the risk into bonds to pay a dollar to determine the portion of the spot rate. He uses no arbitrage valuation techniques. This method can be used for corporate bonds and direct-traded derivatives [15]. Duffee (1998) that the bond spreads depends on corporate bonds redeemable nature. He investment grade corporate bonds proved the hypothesis. Although government bond yields rise when callable corporate bonds and non-callable corporate bond spreads have declined, but for callable bonds this relationship more robust [16]. Carr, Linetsky (2010) will be seen as a breach of the stock price process changes over time Markov diffusion process, with volatility and default density [17].

Dai, Singleton (2003) studied the dynamic term structure theory and empirical fitting historical changes in the yield curve. They observed the dynamic term structure model of government bonds or swaps yield curve fitting case in which risk factors obey diffusion, jump diffusion or conversion system [18]. Duffie and Lando (2001) studied the incomplete information corporate bond credit 
spread term structure, he assumed that bond investors can not directly observe the bond issuer's assets, regularly received only incomplete reporting of financial information, subject to the company's assets geometric Brownian motion, he used the conditions for financial assets, distribution of data, compared with the complete information, there is a breach of this density process, the conditional distribution of assets from the liquidated density obtained in the period. Credit spreads have the characteristics of financial information [19].

There are many scholars use the term structure model to analyze the bond commodity futures term structure. Schwartz, Smith (2000) were studied using two-factor model of commodity prices, short-term price model allows the presence of mean reversion, He found the exact model did not change the reaction convenience yield over time, but this model with stochastic convenience yield equivalent model, the authors estimate the petroleum futures contract parameters [20]. Casassus, Collin-Dufresne (2005) includes a three-factor model with spot commodity prices, interest rates and the convenience yield, which rely on the convenience yield spot prices and interest rates, while the risk premium over time. These will cause the spot price mean reversion. Empirical results show that crude oil and copper spot price depends on the convenience yield, suggesting that risk-neutral price when obedience mean reversion. Gold, risk silver, copper showing changes over time premium [21]

Duffee (2005) Markov process will be introduced in the credit risk model. He focuses on the company's credit risk and credit derivatives pricing. Affine process include the presence, dynamic term structure model with stochastic volatility, option pricing jump. Applications include default risk default correlation [22].

Yu, Zivot (2011) expands the dynamic Nelson-Siegel three-factor model, they used nine different bond rating on state-space method valuation. They found that the dynamic Nelson-Siegel model is more accurate than other forecasting methods. Especially for short-term investment grade bonds and long-term high-yield bonds. But the dynamics of short-term high-yield bonds varies with time, and the parameter of instability [23].

\section{Related Review}

Study abroad on the term structure of interest rates has many foreign scholars Kalman filtering method and Monte Carlo method empirical analysis of foreign studies focus on futures and spot commodity prices, corporate bond pricing, some of the company Study on bond yields spreads and bond yields, foreign study found that model can fit the corporate bond pricing. Domestic bonds are mainly research on the term structure, scholars found that the term structure model can fit Treasury prices and yields. At present, the domestic research firm bond maturity structure is very small. This paper studies the Shanghai Stock Exchange Kalman filtering method and the Shenzhen Stock Exchange corporate bond yields Term structure. There is no scholar Kalman filter time series model of corporate bond yield spreads influencing factors were analyzed.

\section{References}

[1] Dai Q, Singleton K J. Specification Analysis of Affine Term Structure Models [J]. The Journal of finance, 2000, 4(5): 1943-1978.

[2] Vasicek, Oldrich A. An equilibrium characterization of the term structure [J]. Journal of Financial Economics, 1977, 5: 177-188.

[3] Cox, John C, Jonathan E, Ingersoll, Stephen A, Ross. A theory of the term structure of interest rates [J]. Econometrica, 1985, 53: 385-408.

[4] Duffee R. Term Premia and Interest Rate Forecasts in Affine Models [J]. Journal of finance, 2002, 6(1): 405-443.

[5] Jong D F. Time Series and Cross-section information in Affine Term-Structure Models [J]. 
Journal of Business \& Economic Statistics, 2000, 3(18): 300-314.

[6] Duffie, Kan. A yield-factor model of interest rates [J]. Mathematical Finance, 1996, 6(4): 379-406.

[7] Longstaff A, Schwartz S. A Simple Approach to Valuing Risky Fixed and Floating Rate Debt [J]. The Journal of finance, 1995, 3(3): 789-819.

[8] Vasileiou A, Vasileiou G. An inhomogeneous semi-markov model for the term structure of credit risk spreads [J]. Advances in Applied Probability, 2006, 38(1): 171-198.

[9] Lamoureux G, Witte H. Empirical Analysis of the Yield Curve: The Information in the Data Viewed through the Window of Cox, Ingersoll, and Ross [J]. Journal of finance, 2002, 6(3): 1479-1520.

[10] Duan, Simonato. Estimating and Testing Exponential-Affine Term Structure Models by Kalman Filter [J]. Review of Quantitative Finance and Accounting, 1999, 13: 111-135.

[11] Duarte. Evaluating an Alternative Risk Preference in Affine Term Structure Models [J]. The Review of Financial Studies, 2004, 17(2): 379-404.

[12] Dai Q, Singleton K J. Expectation puzzles, time-varying risk premia, and affine models of the term structure [J]. Journal of Financial Economics, 2002, 63: 415-441.

[13] Cheridito, Filipovic, Kimmel L R. Market price of risk specifications for affine models: Theory and evidence[J]. Journal of Financial Economics, 2007, 83: 123-170.

[14] Lando. On Cox Processes and Credit Risky Securities [J]. Review of Derivatives Research, 1998, 2: 99-120.

[15] Jarrow A R, Turnbull M S. Pricing Derivatives on Financial Securities Subject to Credit Risk [J]. Journal of finance, 1995, 5(1): 53-85.

[16] Duffee R G. The Relation Between Treasury Yields and Corporate Bond Yield Spreads [J]. Journal of finance, 1998, 6 (53): 2225-2241.

[17] Carr, Linetsky. Time-changed markov processes in unified credit-equity modeling [J]. Mathematical Finance, 2010, 4(20): 527-569.

[18] Dai, Singleton. Term Structure Dynamics in Theory and Reality [J]. The Review of Financial Studies, 2003, 3(16): 631-678.

[19] Duffie, Lando. Term structure of credit spreads with incomplete accounting information [J]. Econometrica, 2001, 3(69): 633-664.

[20] Schwartz, Smith J E. Short-Term Variations and Long-Term Dynamics in Commodity Prices [J]. Management Science, 2000, 7(46): 893-911.

[21] Casassus, Collin D. Stochastic Convenience Yield Implied from Commodity Futures and Interest Rates [J]. The Journal of finance, 2005, 5: 2283-2331.

[22] Duffe D. Credit risk modeling with affine processes [J]. Journal of Banking \& Finance, 2005, 29: 2751-2802.

[23] Yu W, Zivot E. Forecasting the term structures of Treasury and corporate yields using dynamic Nelson-Siegel models [J]. International Journal of Forecasting, 2011, 27: 579-591. 